\title{
LO ESTÉTICO COMO ACCESO A LA REALIDAD EN EL PENSAMIENTO ESPAÑOL CONTEMPORÁNEO
}

\author{
ALFREDO ESTEVE MARTÍN \\ Universidad Católica de Valencia San Vicente Mártir
}

\begin{abstract}
RESUMEN: El pensamiento estético ha sido una constante en la tradición filosófica española contemporánea, y seguramente no ha sido por casualidad. Podemos preguntarnos por qué. Como es sabido, nuestro pensamiento durante el siglo XX ha tenido como uno de sus principales focos de atención «lo vital» 0 , mejor dicho, la integración de razón y vida: desde el gran paso que supuso el raciovitalismo orteguiano, la preocupación por este tema ha sido una constante entre nuestros autores. Con su pensamiento Ortega se une a una tradición de autores como Schopenhauer, Nietzsche o Bergson, en la que se pone de manifiesto cómo es preciso pensar en diversos modos de ejercer la razón al meramente conceptual o teorético. Esta nueva dimensión se encuentra vinculada al ámbito de lo estético. Así, lo estético deja de ser únicamente una reflexión sobre el arte y la belleza, para erigirse en un modo diverso de acceso a lo real, tal y como se puede apreciar en el mismo Ortega, en d'Ors, Zambrano... y Zubiri, quien con su inteligencia sentiente lleva a su máxima expresión - a mi modo de ver- el acceso estético a la realidad, tal y como explica en sus breves «Reflexiones filosóficas sobre lo estético».
\end{abstract}

PALABRAS CLAVE: razón vital; estética; apertura a la realidad; Zubiri; estratos metafísicos.

\section{Aesthetics as Access to Reality in Contemporary Spanish Thinking}

ABSTRACT: Aesthetic thinking has been a constant in the contemporary Spanish philosophical tradition, and certainly not by chance. We can ask ourselves why. As it is well known, our thinking during the twentieth century has had as one of its main focuses of attention on the integration of reason and life: from the great step that the Ortega's ratiovitalism supposed, the concern for this topic has been a constant among our authors. With his thought Ortega joins a tradition of authors such as Schopenhauer, Nietzsche or Bergson, in which it becomes clear how necessary it is to think in different ways of exercising reason against the merely conceptual or theoretical one. This new dimension is linked to aesthetics. Thus, aesthetics ceases to be only a reflection on art and beauty, to become a diverse mode of access to reality, as can be seen in the same Ortega, d'Ors, Zambrano ... and Zubiri, who brings with his sentient intelligence the aesthetical access to reality to his highest expression -in my view -, as he explains in his brief "Philosophical Reflections on the Aesthetic».

KEY WORDS: vital reason; aesthetics; openness to reality; Zubiri; metaphysical strata.

\section{INTRODUCCIÓN}

Es característica en el pensamiento de comienzos del siglo XX una preocupación que, si bien podemos encontrar vestigios de ella con anterioridad, sí que 
es cierto que es en esta época cuando los esfuerzos empiezan ya a cristalizar de forma relevante en distintos autores. Esta preocupación se puede articular alrededor de la necesidad de superar el idealismo moderno sin recaer en el realismo clásico, lo cual posee una deriva muy significativa como es la posibilidad de ejercer la razón de modo diverso al acostumbrado (más reflexivo o teorético). Efectivamente, el acceso a la realidad desde un ejercicio meramente especulativo de la razón se tornaba problemático, e incluso insuficiente, para salvar los dos abismos que comentaba el singular Nietzsche (las imágenes mentales y su expresión lingüística) desde la consideración pura de la razón; el cual, apoyándose en su amado y odiado Schopenhauer, proponía acceder a la realidad empleando otra vía, que en su caso era lo estético ${ }^{1}$. Pero como digo, y es de sobra sabido, esta preocupación era una constante de la época, presente en distintos autores desde distintos enfoques: desde una perspectiva más metafísica se podría situar a Bergson, desde otra más histórica o hermenéutica a Dilthey, en la fenomenológica a Husserl... por citar a los más importantes.

Pues bien, de todo ello se hizo eco nuestro Ortega y Gasset, quien supo aunar estas diferentes tradiciones ofreciéndonos una síntesis ejemplar en su raciovitalismo ${ }^{2}$. La figura orteguiana se me antoja como el cuello estrecho de un reloj de arena: antes de él se encuentra dispersa en diferentes escuelas una reflexión filosófica plural que él es capaz de aglutinar de alguna manera en su razón vital; para que, acto seguido, ésta continúe su curso abriéndose de nuevo en distintas líneas representadas por distintos autores de nuestra tradición española. El «caudal filosófico» se estrecha en él para, a partir de él, volver a ensancharse con diferentes matices, aspectos y enfoques, que no son sino los propios de nuestros autores.

\section{LA SOLUCIÓN ORTEGUIANA A LA METAFÍSICA}

El análisis de la influencia en Ortega de otros filósofos es una tarea que no se puede pasar por alto a la hora de comprender su pensamiento porque, parafraseando a Jesús Conill (quien, aunque en este contexto se refiere en concreto a F. Nietzsche ${ }^{3}$, creo que su valoración se puede extender al resto de autores), sus sombras son alargadas. Y será gracias a estas «sombras alargadas» que Ortega podrá aprovechar sus respectivos pensamientos en orden a fraguar lo que para él será su principal preocupación: recuperar la vida ante el imperio de la sola razón. El lugar adecuado de la razón no está por encima de la vida,

\footnotetext{
1 Nietzsche, F., «Sobre la verdad y la mentira en sentido extramoral», 34 y ss. (Las referencias completas de las obras citadas aparecen en la bibliografía, al final).

2 Es conocida la influencia de distintos pensadores en Ortega y Gasset. En este trabajo me he apoyado en las reflexiones de Jesús Conill sobre la relación del pensamiento orteguiano con el de Nietzsche, en las de Juana Sánchez-Gey con el de Kant y Bergson, y en las de José María Atencia con el de éste último ( $c f$. bibliografía).

3 Cf. Conill, J. «De la razón pura a la razón vital orteguiana a través de Nietzsche», 72.
} 
sino a su servicio, tal y como nos explica — por ejemplo— en Ensimismamiento y alteración $n^{4}$. Desde esta perspectiva, lo ajeno al ejercicio teorético de la misma ya no tiene que ser entendido como algo irracional, sino todo lo contrario: como elementos «impuros» de la misma — si se quiere-que, lejos de falsearla, la arriman hacia lo que es su uso más legítimo; porque todas estas impurezas lo que hacen no es sino «vitalizar» la razón, hacerla aterrizar e incorporarla a las estructuras vitales de cada cual; encarnarla, en definitiva.

Si bien Ortega y Bergson coinciden en la necesidad de superar el enfoque clásico y moderno de la metafísica atendiendo a la dinamicidad de lo real y a la dimensión vital humana, Bergson lo realiza desde una dimensión que va más allá de lo estrictamente vital y que abre al ser humano a un orden que lo trasciende (el élan vital) y que es de difícil conceptualización (tarea a la que Bergson no renuncia), mientras que Ortega se queda en una dimensión más intrahistórica, pugnando por mantener la relevancia de lo racional aun en esta perspectiva vital ${ }^{5}$. Aunque no se trata aquí de analizar lo que sea la razón vital orteguiana, sí que quisiera destacar alguna de sus claves. Una de ellas es precisamente ésta: cómo Ortega va mucho más allá de un miope empirismo, para atender a una dimensión experiencial de la vida a cuya luz hay que leer el pensar. Porque, efectivamente, Ortega entiende que el conocimiento no puede ir más allá de lo empírico; pero también es cierto que la aprehensión empírica que se pueda tener de la realidad no sólo es la que se pueda obtener mediante nuestros sentidos fisiológicos, sino que puede ser extendida para alcanzar una dimensión experiencial desde la cual poder configurar la vida tanto a nivel individual como social:

«Ortega va a aceptar un conocimiento que no tiene capacidad para aprehender lo que no es empírico, pero sí admitirá desde su modelo antropológico la capacidad del ser humano para progresar en orden a una interpretación personal de la realidad que le rodea y a una interpretación colectiva como progreso genérico de la humanidad». ${ }^{6}$

Esta dimensión experiencial está íntimamente ligada a nuestras vidas; unas vidas que, en tanto que poseen una innegable y radical estructura biológica, participan de las mismas categorías orgánicas que se pueden encontrar en el fenómeno «vida» globalmente considerado. Porque en su raciovitalismo, Ortega considera este fenómeno global que podemos entender como «vida» de modo simultáneo con aquellos elementos específicamente humanos, confluyendo en la «vida humana» los elementos biológicos con los específicamente humanos.

Es fácil entender el momento vital del raciovitalismo orteguiano en términos de lo que es el despliegue o el desarrollo de nuestras vidas: su carácter de proyecto, de futurición, de tarea, de quehacer... Independientemente de que

\footnotetext{
Cf. Ortega y Gasset, J., «Ensimismamiento y alteración», OC V, 304.

Cf. Atencia, J. $\mathbf{M}^{\mathrm{a}}$, «Razón, intuición y experiencia de la vida», 96.

6 Sánchez-Gey Venegas, J., "Origen común y desarrollo divergente en Bergson y Ortega», 64-65.
} 
esto quede englobado en él, si nos fijamos Ortega lo entiende fundamentado primariamente en esta dimensión biológica que estamos comentando, dimensión biológica o animal que puede ser agrupada bajo la categoría de instinto, a diferencia de estos elementos humanos propios del ejercicio de su razón, sin los cuales la vida humana sencillamente no sería humana, y que podrían englobarse en su capacidad de fantasía. El hombre es un animal, pero no es del todo un animal: es un animal fantástico.

"A diferencia del antropoide, que vive "sin problemas" lo que tiene que hacer, el hombre "ha perdido el don principal zoológico que es el sistema de sus instintos", al haber irrumpido en él una "potencia subversiva", la fantasía, que le capacita para vencer al instinto» ${ }^{7}$.

Pero el instinto no es que desaparezca, sino que permanece en nuestras estructuras como una potencia humana, junto a la fantasía. Una fantasía sin su dimensión instintiva aparecería desfondada, un instinto sin su dimensión fantástica no sería humano. La fantasía, pues, no sustituye a lo instintivo, sino que se monta sobre ello. Lo instintivo, lo fisiológico, lo corporal, será la base sobre la cual esbozar el nuevo modelo de razón, una razón que no sobrevuela nuestra dimensión vital, sino que se entronca íntimamente con ella, y cuya finalidad ya no será primariamente conocer la realidad sino salvar a la persona.

\section{Un testigo PROBLEMÁtico}

Hemos visto cómo en Ortega es fundamental la dimensión biológica de la razón, sin la cual difícilmente se podría comprender en su radicalidad la razón vital: como dice la profesora Sánchez-Gey, «la razón es para Ortega acción vital ${ }^{8}$, de modo que el conocer es subsidiario al vivir. Pues bien, a mi modo de ver se puede establecer aquí un puente desde Ortega hacia el pensamiento de Xavier Zubiri. Quizá sea El tema de nuestro tiempo ${ }^{9}$ la obra orteguiana que dedica más temáticamente a la razón vital; efectivamente, en ella, y con su característica pedagogía, Ortega nos va llevando de una razón pura hacia una razón anclada en las estructuras vitales del ser humano. Singularmente relevante - a mi modo de ver- es el cap. V — «El doble imperativo»—, en el que Ortega nos explica esa doble cara que posee el fenómeno vital humano, y que propicia que ante el ser humano actúen dos polos de atracción: el propio de nuestra biología, y el propio de nuestra cultura. "Así, la actividad intelectual gravita, de una parte, hacia el centro de la necesidad biológica; de otra, es requerida, imperada por el principio ultravital de las leyes lógicas ${ }^{10}$. Es decir, que no cabe

7 Conill, J., op. cit., 82

8 Sánchez-Gey Venegas, J., "Origen común y desarrollo divergente en Bergson y Ortega», 63.

9 Ortega y Gasset, J., OC III, 141-203.

10 Ortega y Gasset, J., Op. cit., 169. 
diseccionar nuestra inteligencia únicamente hacia el ámbito cultural, sino que, sin menospreciar éste de ningún modo, debe atender simultáneamente a la dimensión vital en la que se incardina. Las funciones de la cultura son también funciones biológicas y, por este motivo, «la cultura no puede ser regida exclusivamente por sus leyes objetivas transvitales, sino que, a la vez, está sometida a las leyes de la vida», tal y como nos dice un poco más adelante.

A su modo de ver, tanto en la época clásica como en la medieval y en la moderna, ha predominado tenazmente la dimensión culturalista, lo cual entraña un grave riesgo, a saber: adecuar nuestra vida a las declaraciones de la razón olvidándonos de sus exigencias específicas, «con lo cual acontecerá que la cultura no se realiza en nosotros y queda como una superficie de ficción sobre la vida efectiva» ${ }^{11}$. El resultado será una especie de «ficción colectiva inconsciente», ficción colectiva inconsciente que vendría a coincidir con el horizonte de comprensión acostumbrado: por un lado, los principios, las teorías, etc.; y por el otro, la existencia, la vida. Y no siempre iban a la par, lo que generaba necesariamente todo tipo de conflictos. Permítaseme citar un amplio texto del propio Ortega, en el que queda perfectamente explicada su postura:

«No se habría llegado a tal disociación entre las normas y su permanente cumplimiento, si junto al imperativo de objetividad se nos hubiese predicado el de lealtad con nosotros mismos, que resume la serie de los imperativos vitales. Es menester que en todo momento estemos en claro sobre si, en efecto, creemos lo que presumimos creer; si, en efecto, el ideal ético que "oficialmente" aceptamos interesa e incita las energías profundas de nuestra personalidad. Con esta continua mise au point de nuestra situación íntima, habríamos ejecutado automáticamente una selección en la cultura, y hubiéranse eliminado todas aquellas formas de ella que son incompatibles con la vida, que son utópicas y conducen a la hipocresía. Por otra parte, la cultura no habría ido quedando cada vez más distante de la vitalidad que la engendra y, en su espectral lejanía, condenada al anquilosamiento» ${ }^{12}$.

Efectivamente, la disociación entre la razón y la vida provoca división, conflicto; y la apuesta orteguiana pasa por unir ambas dimensiones. Démonos cuenta de que Ortega insiste en mantener lo cultural y lo biológico, lo racional y lo vital, pues es fácil que personas menos afines a su pensamiento sitúen a lo vital por encima de lo racional cuando entiendo que esa no era la postura orteguiana: recuperar lo vital no implica para nada desestimar lo racional. Lo que no podemos dejar de plantearnos, por otro lado, es cómo se hace esto de modo efectivo, es decir, cómo saber si lo racional incita efectivamente a «las energías profundas de nuestra personalidad»o, por el contrario, seguimos engañándonos, aunque dicho engaño ya no pertenezca exclusivamente al ámbito cultural o racional sino que integre ya dimensiones del biológico o vital.

11 Idem.

12 Ibidem, 172. 


\section{Más allá de Ortega}

Este enlace que comentaba con el pensamiento zubiriano, a mi modo de ver recibe un aliento importante atendiendo al somero análisis que realiza Ortega de las facultades humanas en la obra mencionada. A la luz de su recuperación de lo vital, Ortega entiende que las facultades humanas - pensamiento, voluntad, sentimiento- no pueden ser ejercidas atendiendo a uno sólo de estos dos imperativos, como ha sido el caso en nuestra tradición occidental en la que se ha incidido en el imperativo cultural desplazando el biológico o vital. A su modo de ver, las facultades deben ser ejercidas atendiendo a ambos imperativos, a la luz de los cuales adoptará una dimensión específica: «Nuestras actividades necesitan, en consecuencia, ser regidas por una doble serie de imperativos, que podrían recibir los títulos siguientes» ${ }^{13}$. Y, a continuación, expone la siguiente tabla:

\begin{tabular}{|c|c|c|}
\hline & \multicolumn{2}{|c|}{ IMPERATIVO } \\
\hline & CULTURAL & VITAL \\
\hline Pensamiento & Verdad & Sinceridad \\
\hline Voluntad & Bondad & Impetuosidad \\
\hline Sentimiento & Belleza & Deleite \\
\hline
\end{tabular}

Así, el pensamiento se puede considerar desde la verdad o desde la sinceridad; la voluntad, desde la bondad o desde la impetuosidad; y el sentimiento, desde la belleza o desde el deleite. Esto es, cada facultad debe atender a su origen vital en el ser humano, así como a su dimensión cultural.

Este anclaje en lo biológico también se encuentra presente en Xavier Zubiri, quien dedicó no pocos esfuerzos a reflexionar sobre las facultades humanas. Al igual que Ortega, el filósofo vasco es consciente de que la inteligencia no se monta sobre sí misma, sino que necesariamente se encuentra arraigada en unas estructuras constitutivas que no sólo la soportan, sino que también la posibilitan, y que son de carácter biológico o fisiológico. Es aquí donde hay que situar su afirmación de que la inteligencia no sustituye al sentir animal (al «puro sentir»), sino que se monta sobre él para facultar la inteligencia sentiente ${ }^{14}$. Si Ortega barajaba los términos instinto y fantasía, Zubiri hará lo propio con los de «puro sentir» e «inteligencia», el primero más propio del reino animal y el segundo específicamente humano (independientemente de que en la fisiología humana se den procesos que se pueden incluir en el ámbito del puro sentir, pero que no muestran la especifidad humana). Con las salvedades pertinentes, mientras que el instinto o el puro sentir desencadenan procesos determinados con mayor o menor holgura en los comportamientos, la fantasía o la inteligencia (sentiente) abren un inespecífico ámbito de comportamientos y respuestas.

13 Ibidem, 171.

14 Cf. ZubiRI, X., Sobre el hombre, 370. 
Creo que es razonable afirmar que la idea que subyace de fondo en ambos autores es análoga: lo específicamente humano emerge sin descuidar su origen fisiológico, todo lo contrario, manteniéndolo en su ejercicio propio.

A la luz del pensamiento zubiriano, la inteligencia humana abre al proceso sentiente a un ámbito de inespecificidad en el que el individuo humano ya no sabrá a qué atenerse (a diferencia de cualquier otro animal), y necesitará «hacerse cargo» de la realidad para poder desenvolverse en ella, sencillamente para poder vivir, para poder ser una especie viable evolutivamente. Es aquí donde hay que situar su inteligencia sentiente, una facultad que es primariamente biológica, y que sólo secundariamente se modalizará en sus usos cognitivos, que son los más corrientes por otro lado. Y del mismo modo que en la facultad intelectiva Zubiri integra esta doble dimensión resultando la «inteligencia sentiente», hace lo propio-igual que Ortega- con la voluntad y con el sentimiento, hablando de «voluntad tendente» y de «sentimiento afectante», denominaciones dobles con las que quiere poner de manifiesto la presencia tanto de la dimensión fisiológica como de la específicamente humana. En realidad, lo que Zubiri quiere hacernos ver es cómo el puro sentir animal se eleva a un sentir inteligente humano, en el que la inteligencia en su ejercicio propio no puede desvincularse del haber humano constitutivamente fisiológico.

\section{LA APERTURA ESTÉTICA A LA REALIDAD}

Habíamos dejado abierta una cuestión importante, como es la posibilidad de averiguar si lo racional incita efectivamente a «las energías profundas de nuestra personalidad», tal y como exponía Ortega. A mi modo de ver, el pensamiento zubiriano puede sernos de gran utilidad en esta tarea, sobre todo a la luz de sus "Reflexiones filosóficas sobre lo estético»" ${ }^{15}$, las cuales nos permiten leer desde un enfoque novedoso su inteligencia sentiente. No podemos olvidar que la facultad humana a la que aludía Zubiri no es sólo una inteligencia sentiente, sino que es sobre todo una inteligencia sentiente. Y esto es fundamental, porque tal y como nos dice él mismo, la realidad no es primariamente inteligida sino sentida ${ }^{16}$; y si la realidad es primariamente sentida, y nuestro sentir no es un puro sentir sino un sentir inteligente, quiere decirse que la realidad está presente físicamente en el ejercicio de nuestra inteligencia.

Esto que desde el punto de vista de nuestra sensibilidad es evidente (la presencia de la realidad en nuestra percepción fisiológica), en el ejercicio de nuestra inteligencia no lo es tanto. De hecho, es más que frecuente que el ser humano ejerza su inteligencia sin esta dimensión sentiente, modo que Zubiri denomina «concipiente». Zubiri se hace eco de lo que ya denunció Ortega en su día: el filósofo vasco también es consciente de ese tópico que ha consistido en ejercer la inteligencia sin

15 Publicadas en el volumen Sobre el sentimiento y la volición.

16 ZuBiri, X., El hombre: lo real y lo irreal, 92. 
que este arraigo físico en la realidad se encuentre debidamente articulado, dando lugar al desempeño de una «inteligencia concipiente», con el riesgo en su ejercicio de no tener presente la realidad sobre la que está ejerciendo su inteligir:

«En el momento en que la inteligencia concipiente no mantiene esta íntima relación, cabe el riesgo de que en su ejercicio sobrevuele aquella realidad a la que pretende dar explicación. La verdad no es tanto una conquista de la inteligencia como un dejar que la realidad por sí misma verdadee en nosotros. Es la realidad la que verdadea, la que nos da la razón o nos la quita» ${ }^{17}$.

De lo que se trata, pues, es de situarse adecuadamente ante la realidad para permitir precisamente que sea ella la que verdadee en nosotros, sin que por ello haya que concluir que no sea preciso solicitar nada al ser humano. Sólo que ya no será un mero esfuerzo intelectivo, sino que será preciso un cambio de actitud ante la realidad, y que será el que posibilite que sea ella la que se actualice veritativamente en nosotros. Este cambio de actitud guarda íntima conexión con lo que María Zambrano denominó conversión ${ }^{18}$, conversión imprescindible porque si no se da, sencillamente no hay encuentro; y no hay encuentro porque la realidad no estará presente en nosotros. Pero no sólo eso, sino que sin esa conversión, no sólo no nos está presente la realidad que pretendemos conocer, sino que tampoco estamos presentes nosotros en nuestra radical profundidad: esa conversión nos posibilita conocer a una tanto la realidad como nuestra propia esencia ${ }^{19}$ porque, en definitiva, el fundamento de la realidad no es otro que nuestro propio fundamento.

Efectivamente, este fundamento último de la realidad también «forma parte de la intimidad humana ${ }^{20}$. Ello pone de manifiesto la gravedad de que el hombre «cuente su historia» sin su consideración, motivo por el cual «es preciso ponerse en el principio y recuperar la capacidad de visión que el hombre tiene y aprender a vivir el carácter sagrado, fundamento de toda la realidad ${ }^{21}$. Esto y no otra cosa es lo que la filósofa malagueña denominó sentimiento originario, porque este fundamento de la realidad no se piensa primariamente, sino que se experiencia, y se experiencia por ser a la vez nuestro fundamento íntimo. En cuanto es pensado, se despoja de su presencia. Y lo que nos propone Zambrano es recuperar este sentimiento originario que propicia un auténtico encuentro experiencial con nuestro íntimo fundamento, "porque en él se presenta la realidad clara de lo que se es y de lo que se quiere ser, la frontera del ser y la nada ${ }^{22}$,

17 Esteve, A., «Posibilidades estéticas de la inteligencia sentiente como acceso a la realidad en Xavier Zubiri», 211.

18 De la que ya se hacía eco Arthur Schopenhauer en El mundo como voluntad y representación ( $c f$. libro III, §48).

19 Cf. Esteve, A., "Zambrano: la creación mediadora», en El arte hecho vida. Reflexiones estéticas de Unamuno, d’Ors, Ortega y Zambrano, cap. 4.

20 Sánchez-Gey Venegas, J., «Lo originario en el pensamiento religioso de María Zambrano», 78.

21 Idem.

22 Ibidem, 79. 
y posibilita una realización personal que, desde este «difícil equilibrio», permanece ajena a posturas dogmáticas.

Como nos dice la profesora Sánchez-Gey, lo que pretende Zambrano es recuperar nuestra capacidad para poder intuir esa realidad primigenia, mediante el «sentir originario que tiene que ver con la relación del ser humano con la realidad que le rodea, consigo mismo y con el fundamento absoluto» ${ }^{23}$; un sentir que es previo a cualquier tipo de conceptuación, de razonamiento o de juicio, y en el que prima más un «dejarse hacer» que un «hacer activo»: es más una acogida que una conquista, pero no es pura pasividad sino que es una receptividad activa, por decirlo así. Su resultado no es erudición, sino unidad en el ser. Como sabemos, éste es el núcleo de su razón poética.

Como vemos, este testigo orteguiano no implica únicamente un modo distinto de entender la existencia humana (uniendo lo racional con lo vital), sino que abre puertas para que este este modo diferente de entendernos a nosotros mismos revierta sobre el modo en que aprehendemos la realidad. Lo vital, lo sentiente, no sólo repercute en el desempeño de nuestra existencia, sino que esta ampliación de la razón posee también una gran relevancia en tanto que nos permite aprehender la realidad según dimensiones no estrictamente cognitivas, sino sentientes, afectivas... estéticas ${ }^{24}$.

\section{LA FUNDAMENTACIÓN ZUBIRIANA}

Como decía más arriba, a la luz de lo visto y desde las «Reflexiones filosóficas sobre lo estético» ${ }^{25}$ de Xavier Zubiri, a mi juicio se puede fundamentar filosóficamente esta apertura a la realidad más allá de un ejercicio meramente teorético de la inteligencia humana. Ya hemos destacado la relevancia de lo sentiente en su inteligencia sentiente. Pues bien, del mismo modo que lo sentiente no está reducido al ámbito de la percepción sensible, a mi modo de ver tampoco lo estético está para el filósofo vasco reducido al ámbito de lo artístico. El punto de confluencia entre estos dos «ir más allá» se puede establecer en el ámbito del sentimiento, de lo afectivo. Lo sentiente tiene que ver con la percepción sensible, sí, pero no sólo con la percepción sensible empírica sino

23 Ibidem, 80.

24 Esto se pone de manifiesto también en la reflexión estética de Ortega. Para el filósofo madrileño, en la realidad se puede observar el correlato de lo vital propio del ser humano, esto es, su carácter dinámico. La realidad no es un conjunto de entes que están ahí, estáticamente, sino un «haz de relaciones» que subyace a lo aprehensible por nuestros sentidos y que fundamenta dicha manifestación en sus combinaciones entre materia y forma, tensión en cuyo despliegue es capaz de manifestarnos el artista. Tal y como nos explica López Quintás (cf. López QuinTás, A., El pensamiento filosófico de Ortega y d'Ors, 151-188), lejos de ese reduccionismo empírico que comentábamos, lo que busca Ortega es reivindicar lo vital, lo dinámico, frente a lo objetivo, lo cósico, lo racional; pero no para abandonarlo a su suerte, sino para integrarlo en una razón capaz de obtener un conocimiento más global, ámbito en el que lo estético cobra especial relevancia.

25 Incluidas en el volumen Sobre el sentimiento y la volición (cf. bibliografía). 
sobre todo con una instalación física en la realidad, lo cual supone un modo radicalmente diverso de entender nuestra relación con la realidad, y que nos abre a un encuentro con la misma en el que la dimensión afectiva adquiere carta de naturaleza. Del mismo modo, lo estético, evidentemente, tiene que ver con el arte o con la belleza, pero no sólo con el arte y con la belleza sino también con nuestro modo de aprehenderlos, es decir: con el sentimiento estético. Un sentimiento estético que, por otra parte, puede aprehender la belleza más allá del ámbito artístico, para extender su campo de acción a toda la realidad ${ }^{26}$. En cualquier caso, se puede observar cómo desde la consideración de la dimensión sentiente que nos instala físicamente en la realidad, por un lado, y desde la aprehensión de la belleza de esa realidad por el otro, se tiende hacia un punto de confluencia que no es otro que nuestra dimensión afectiva.

Para Zubiri el papel primario de la inteligencia no es cognitivo sino sentiente: lo primario de la inteligencia es sentir la realidad, y sentirla por impresión. Se trata de una impresión de realidad, en la que se pueden distinguir dos momentos: el de «impresión» o del contenido de lo que se siente, y el de «realidad» o el momento formal que compete al inteligir. Y, si esto es así, efectivamente en ese momento primario y radical de la inteligencia sentiente el ser humano es capaz de estar verdaderamente en contacto, no sólo intelectivo sino también físico, con la realidad. $\mathrm{O}$, dicho de otro modo: podemos no sólo pensar la realidad, sino también «tocarla», no sólo con nuestros sentidos (lo cual es evidente), sino también con nuestra inteligencia, porque el caso es que nuestra inteligencia no es una mera inteligencia concipiente, sino que ella posee también una dimensión sentiente. No se debe pensar que la dimensión sentiente de la inteligencia se corresponda con el ámbito de la sensibilidad o de lo afectivo. Es otra cosa. De lo que se trata es de poner de manifiesto esa otra dimensión física que está presente en el ejercicio de la inteligencia, y que por ende también se da en las otras facultades humanas: en la voluntad (voluntad tendente) y cómo no en la afectividad (sentimiento afectante).

Ahora bien, ¿de qué realidad estamos hablando?, ¿cuál es esa realidad que está presente físicamente en nuestras facultades? Zubiri distingue en la realidad distintos niveles de actualización, una gradación metafísica de la misma, según la cual hay distintos niveles de aprehensión, invitando a un recorrido en el que, partiendo del nivel más superficial, poco a poco se bucea en estratos cada vez más hondos de la misma. No es que se trate de realidades distintas, sino que es una misma y única realidad (sólo hay una) pero actualizada a distintos niveles, lo cual da lugar a los siguientes estratos ${ }^{27}$. Ante una determinada cosa real, cualquiera, se pueden diferenciar en ella su momento talitativo (según el cual la cosa es «tal» cosa, relacionado con sus notas y contenido), su momento de realidad (por el que la cosa es «más que» tal cosa), así como su momento trascendental de pertenencia a «la» realidad respectiva (la cosa es más que

26 Cf. ibidem, 323.

27 Cf. Zubiri, X., «Respectividad de lo real», 36. 
«su» forma y modo de realidad, es realidad «abierta como realidad» sin más, constituyendo el mundo). Pues bien, de esta manera, con cualquiera de nuestras facultades nosotros podemos actualizar la realidad en cualquiera de estos tres estratos, también la facultad afectiva. De hecho, es una empresa que Zubiri acomete en el texto que estamos comentando. La tarea que quedaría pendiente sería «educarnos» para la aprehensión de la realidad en clave de profundidad; tarea a la que nos invita María Zambrano y que está íntimamente relacionada con el análisis de lo que para Zubiri es el sentimiento estético o, mejor dicho, con la dimensión estética del sentimiento.

Vaya por delante que, para Zubiri, un sentimiento no es algo exclusivamente subjetivo. Es consciente de que este enfoque difiere notablemente del planteamiento acostumbrado, el cual asume - por lo general— que lo sentimental no tiene por qué tener mayor referencia a la realidad, y que por ende se trata de algo de lo que no tenemos que dar cuentas: nuestros sentimientos son nuestros, y no tenemos por qué dar razón de ellos; sencillamente los sentimos y ya está. Todo lo cual ha derivado en negar su legítima relevancia, dado que sin la dimensión emocional el ser humano se encontraría gravemente mermado. ¿Nos podemos imaginar a una persona sin su dimensión afectiva? Y siendo lo emocional algo tan importante en la vida, ¿es legítimo relegarlo a ese ámbito de lo meramente subjetivo? Para Zubiri, no, ni mucho menos; en su opinión, en todo sentimiento, igual que en toda intelección y en toda acción, hay una indudable referencia a la realidad:

«Hay, pues, estos dos aspectos: el sentimiento como acto, y la realidad que en ese acto nos está presente, de la misma manera que hay el acto de voluntad como acto, y la forma en que la realidad me está presente, o el acto de la intelección como acto, y la forma que en la intelección me es presente la realidad ${ }^{28}$.

Ello no quiere decir que distintos individuos deban sentir lo mismo ante una misma realidad, ni mucho menos; de lo que se trata es de poner de manifiesto de que, en cualquier sentimiento, hay una versión a la realidad. Pues bien, es precisamente esta versión a la realidad la que constituye la dimensión estética del sentimiento. Es decir: Zubiri opina que no hay «un» sentimiento estético como tal, sino que «en realidad habría que decir "lo estético de todo sentimiento" ${ }^{29}$. Nuestro autor entiende que hablar de un sentimiento estético es una sustantivación de algo que no es sustantivable; no hay estrictamente un sentimiento estético, sino que todo sentimiento posee una dimensión estética, que es distinto. No se trata de ningún sentimiento especial, sino de cómo afecta estéticamente la realidad al sujeto. Por su parte, hay en la realidad una dimensión que es la que permite que el ser humano pueda ser afectado tónicamente por ella, proceso que Zubiri denomina atemperamiento. El hombre posee una dimensión indudablemente afectiva, tónica; y el modo de estar acomodado

28 ZuBIRI, X., Sobre el sentimiento y la volición, 336.

29 Ibidem, 347. 
tónicamente a la realidad (de estar atemperado) es precisamente el sentimiento ${ }^{30}$. Lo estético de todo sentimiento es precisamente aquella dimensión según la cual el individuo se atempera a lo real.

Si nos damos cuenta, de este modo un sentimiento es efectivamente algo mío, pero no sólo algo mío, sino que en él se encuentra también presente (de modo atemperante) la realidad. Por eso el sentimiento no es algo meramente subjetivo, sino subjetual ${ }^{31}$. Tanto lo subjetivo como lo subjetual es en ambos casos algo propio de un sujeto; la diferencia estriba en que mientras en lo subjetivo todo pende de las disposiciones del propio sujeto sin mayor relación con la realidad, en lo subjetual, sin dejar de ser también algo propio del sujeto, sí que se da esa referencialidad a la realidad ${ }^{32}$.

Para Zubiri, pues, esta versión a la realidad de un sentimiento es fundamental; tanto como para definir al sentimiento como «un modo de estar realmente en la realidad, o si se quiere, es sentirse realmente en la realidad $»^{33}$. Pues bien, según esta dimensión estética, todo sentimiento debe calificarse como un sentimiento fruitivo o a disgusto, en función de la presencia de la realidad en él según su dimensión atemperante, de modo análogo a como la realidad también está presente en su dimensión de verdad en toda intelección (por lo cual ésta puede ser calificada como verdadera o falsa) y en su dimensión de bondad en toda acción (por lo cual ésta puede ser calificada como buena o mala). El

$30 \quad$ Cf. ibidem, 335.

31 Simplemente hacer notar que en otros lugares Zubiri utiliza este término con otra significación, como en El hombre y la verdad.

32 De modo análogo, fijémonos que este carácter subjetual también es propio de toda intelección y de todo acto volitivo.

33 ZubIRI, X., Sobre el sentimiento y la volición, 332-333. Si nos damos cuenta, es a causa de esta referencia a la realidad que pueden expresarse ideas como aquella de que el corazón es capaz de ver cosas que la inteligencia no ve: son las «razones del corazón» que decía Pascal. Pero más allá de ello, y sin caer en ningún tipo de emotivismo, esto es propio de todo sentimiento, arrimándonos hacia la dimensión estética del pensamiento irónico de Eugenio d'Ors, según la cual se ejerce un tipo de razón no conceptual, y por tanto no reducible a la científica, pero que proporciona también cierto tipo de conocimiento, un conocimiento que provenía más del sentimiento que de la razón ( $c f$. Esteve, A., El arte hecho vida. Reflexiones estéticas de Unamuno, d'Ors, Ortega y Zambrano, 54-55). En palabras del mismo Zubiri: «Todo sentimiento es en cierto modo vidente de la faceta que nos presenta» (ZubIRI, X., Sobre el sentimiento y la volición, 342), porque "presenta un modo de actualidad de la realidad en el enfrentamiento atemperante con ella» (ZuBIRI, X., Sobre el sentimiento y la volición, 343). No toda la realidad es actual al ser humano; sólo aquella que es actualizable por él, o lo que es lo mismo, aquella que sea actualizanda. Y, en segundo lugar, no toda la realidad actualizable es inteligible, sólo aquella que se puede inteligir, o lo que es lo mismo, que sea estrictamente inteligenda. ¿Qué quiere decir esto? Pues que nuestra facultad intelectiva no puede sino dejarse al margen cierto «ámbito» de realidad, la que no sea inteligenda pero sí actualizanda, esto es, que sí es aprehensible sentientemente pero no es actualizable ulteriormente de modo intelectivo. Hay pues, un ámbito de la realidad que si bien es actualizanda no es inteligenda. Ello nos abre sin duda a modos diversos de acceder la realidad, a modos diversos de ejercer la razón más allá de la razón meramente intelectiva, modos que no por no ser intelectivos dejan de actualizarnos la realidad más allá de lo que sea la realidad inteligenda. 
mismo Zubiri es consciente de que es difícil entender así a los sentimientos, que es difícil ver esta referencia a la realidad, referencia a la que sin duda estamos más acostumbrados cuando hablamos de verdad o incluso de bondad.

«Estamos habituados a ver en la realidad solamente el correlato de una intelección o de una volición, y creer que entonces la realidad es lo aprehensible como verum y lo optable como bonum. Tendríamos que habituarnos a introducir en la filosofía esta idea de que la realidad es también formalmente atemperante. La realidad es el "de suyo". Y este "de suyo" queda actualizado no solamente en forma de verdad y de bondad, sino también en forma de atemperante» ${ }^{34}$.

¿Y cómo se da esta referencialidad a la realidad en el sentimiento? Como decíamos, la presencia de la realidad ante nuestras facultades, o nuestra aprehensión de aquélla por parte de éstas, no es unívoca, sino que se puede dar según distintos estratos. Zubiri nos explica que a cada estrato metafísico de realidad le corresponde un modo de referencialidad en la facultad afectiva también distinta. Lo que hace nuestro autor es distinguir distintos niveles estéticos según el estrato de realidad que se actualice, a saber ${ }^{35}$ : el de las cosas en su realidad, el de las cosas por ser reales y el de las cosas en cuanto realidad; que vendrían a corresponderse con los estratos metafísicos mencionados más arriba: el talitativo, el de realidad y el trascendental. Según esta gradación, cada estrato de la realidad tendría un correlato en nuestra afectividad, ofreciendo en cada caso una gradación estética específica: en el primer estrato, el talitativo, la referencia a la realidad se daría según la dimensión de agrado o de desagrado; en el segundo, el de realidad, ya hablaríamos de fruición o disgusto. Démonos cuenta de que, ante determinado sentimiento que tengamos, cualquiera, podemos «leerlo» en clave de agrado o desagrado, con lo cual nos estaríamos moviendo en un estrato superficial; o en clave de fruición o a disgusto, con lo cual hemos trascendido ya ese momento talitativo para atender la cosa en lo que compete a su momento de realidad. Hemos «avanzado» de nivel.

Pero aún queda el tercer estrato, en el que se nos presenta «la» realidad, es decir, la actualización de la realidad no cosificada, sino como ámbito inespecífico, el ámbito mundanal. Pues bien, en este caso, el correlato afectivo se puede cifrar en torno a la experiencia estética. Esta dimensión de trascendencia no implica desentenderse de las cosas: «la» realidad como tal no puede aprehenderse en sí misma, ya que sólo puede ser actualizada «en» las cosas, independientemente de que — como ya sabemos- esa cosa puede ser actualizada según los diferentes estratos.

Hemos alcanzado así cierta gradación a la hora de calificar nuestra afectividad: agrado, fruición y experiencia estética; gradación que se corresponde con una gradación metafísica de la realidad: talitativo, de realidad y trascendental.

34 ZUBIRI, X., Sobre el sentimiento y la volición, 340.

35 C $f$. Zubiri, X., Sobre el sentimiento y la volición, 359 y ss. $C f$. también Esteve, A., «Experiencia artística como caso particular de la experiencia estética, entre Schopenhauer y Zubiri», 193-197. 
Si nos detenemos un momento, este proceso de profundización en el ejercicio de nuestra afectividad, mediante el cual podemos trascender lo cósico para actualizar la realidad trascendental, ¿no guarda cierto paralelismo con lo que María Zambrano denominaba «alcanzar el sentimiento originario»? Y recordemos que ella hablaba de que, para poder alcanzar el sentimiento de lo originario, era precisa cierta conversión en el individuo, cierto «aprendizaje». ¿Por qué? Pues porque, volviendo al lenguaje zubiriano, yo me aprehendo a mí mismo según el estrato en que aprehendo la realidad, ya que de alguna manera yo también soy realidad. O viceversa: yo aprehendo a la realidad según el estrato en que yo me aprehendo a mismo, según el estrato - en definitiva - en que yo desempeño mi vida, que será el estrato desde el que yo configure mi propia sustantividad. Quien se mueva en el estrato talitativo, se aprehenderá afectivamente a sí mismo y a la realidad desde el agrado; cuando se trascienda el estrato talitativo para pasar al estrato de realidad, iremos más allá de lo agradable para calificar afectivamente la realidad y a nosotros mismos desde la fruición estética; y, por último, en la medida en que seamos capaces de trascender este estrato para actualizar «la» realidad mundanal estaremos en disposición de poder experimentar una experiencia estética.

Todo esto supone un aprendizaje, porque lo usual es que la mayoría de nosotros - por lo general- actualicemos la realidad desde el primer estrato, el más común, el más cotidiano: la realidad cósica. Pero en la medida en que podamos ir haciendo presente en nosotros la conversión zambraniana, podremos actualizar la realidad en profundidad, zambulléndonos en su seno, posibilitando nuestra participación en ella mediante la creación de vínculos ambitales de relación cada vez más hondos, como nos explica López Quintás; podremos aprehender ese «haz de relaciones» que - a juicio de Ortega - subyace a lo real. Y en todo ello, el arte - como vieron ambos autores- es una puerta de acceso innegable. En palabras del primero: «El hombre tiene sentimientos por «estar en la realidad». El arte modula ese sentimiento de la realidad, lo eleva a grados muy altos porque inmerge al hombre en las formas de realidad más valiosas» ${ }^{36}$. El arte nos ayuda a trascender lo talitativo, lo cósico:

«El auténtico entorno del hombre no está constituido por una suma de objetos, sino por una trama de acontecimientos relacionales que en buena medida debe el hombre contribuir a realizar. Cobrar conciencia de este carácter ambital interferencial, no simplemente objetivista, de la circunstancia humana significa dar un paso decisivo hacia una actitud de rigurosa creatividad. Y, a la inversa, la práctica de actividades creadoras nos dispone a hacer la experiencia personal del carácter superobjetivista —relacional— de cuanto configura nuestro entorno de hombres» ${ }^{37}$.

La conversión zambraniana - a mi modo de ver- está íntimamente relacionada con nuestro aprendizaje para poder aprehendernos a nosotros mismos y a la realidad según estratos cada vez más profundos, y capacitarnos para así

36 LóPEZ Quintás; A., «El sentimiento estético y la fruición de la realidad», 155.

37 López QuintÁs, A., «La racionalidad propia del arte», 217. 
poder establecer relaciones ambitales de encuentro cada vez más hondas. No podemos dejar de estar entre las cosas entre las que estamos, pero sí que podemos actualizarlas yendo más allá de lo cósico, más allá de lo agradable, para ir hacia nuestra esencia más profunda, hacia lo originario que hay en nosotros y que nos comunica con lo originario de la realidad, con la realidad profunda porque, en definitiva, ¿no se trata del mismo fundamento?

\section{BiBLIOGRAFÍA}

Atencia, J. M M $^{\mathrm{a}}$ 2003). «Razón, intuición y experiencia de la vida. Coincidencias y divergencias entre H. Bergson y J. Ortega y Gasset», en: Logos. Anales del Seminario de Metafísica 36, pp. 67-98.

Conill, J. (2016). «De la razón pura a la razón vital orteguiana a través de Nietzsche», en: Revista de Hispanismo Filosófico 21, pp. 71-92.

Esteve, A. (2018). El arte hecho vida. Reflexiones estéticas de Unamuno, d'Ors, Ortega y Zambrano. Sevilla: Ed. Thémata.

—, (2017). «Experiencia artística como caso particular de la experiencia estética, entre Schopenhauer y Zubiri», en: Pensamiento español contemporáneo: Estética y fenomenología del arte, XII Boletín de estudios de filosofía y cultura Manuel Mindán. Calanda (Terurel): Ed. Fundanción Mindán Manero, pp. 187-198.

—, (2014). «Posibilidades estéticas de la inteligencia sentiente como acceso a la realidad en Xavier Zubiri», en: Scio, Revista de Filosofía 10, pp. 195-216.

López Quintás, A. (1972). El pensamiento filosófico de Ortega y D’Ors. Madrid: Ediciones Guadarrama.

—, (1996). «El sentimiento estético y la fruición de la realidad», en Gracia, D. (Coord); Ética y estética en Xavier Zubiri, Ed. Trotta - Fundación Xavier Zubiri, Madrid, pp. 141-163.

—, (1979). «La racionalidad propia del arte. Creatividad y acceso a lo real»: Realitas IIIIV, pp. 151-228.

Nietzsche, F. $\left(2012^{2}\right)$. Sobre la verdad y la mentira en sentido extramoral y otros fragmentos de filosofía del conocimiento. Madrid: Ed. Tecnos.

Ortega y Gasset, J. (19646) Obras completas, 10 vol. Madrid: Ed. Revista de Occidente.

Sánchez-Gey Venegas, J. (2005). «Lo originario en el pensamiento religioso de María Zambrano", Aurora: papeles del Seminario María Zambrano 7, pp. 78-83.

—, (1985). «Origen común y desarrollo divergente en Bergson y Ortega», Pensamiento: Revista de investigación e Información filosófica 161, pp. 57-67.

Zubiri, X. (2005). El hombre: lo real y lo irreal, Alianza Editorial \& Fundación Xavier Zubiri, Madrid.

—, (1979) «Respectividad de lo real»: Realitas III-IV, 13-43, [acceso 14.12.01], http:// www.zubiri.org/works/spanishworks/Respectividad.htm.

—, (1986). Sobre el hombre. Madrid: Alianza Editorial \& Sociedad de Estudios y Publicaciones.

—, (1992). Sobre el sentimiento y la volición. Madrid: Alianza Editorial \& Fundación Xavier Zubiri.

Universidad Católica de Valencia San Vicente Mártir

alfredo.esteve@ucv.es

Alfredo Esteve Martín

[Artículo aprobado para publicación en enero de 2019] 